Review

\title{
Management of waste electrical and electronic equipment in two EU countries: A comparison
}

\author{
Vincenzo Torretta ${ }^{\mathrm{a}, *}$, Marco Ragazzi $^{\mathrm{b}}$, Irina Aura Istrate ${ }^{\mathrm{c}}$, Elena Cristina Rada ${ }^{\mathrm{b}}$ \\ ${ }^{a}$ Department of Science and High Technology, Insubria University of Varese, Via G.B. Vico 46, I-21100 Varese, Italy \\ ${ }^{\mathrm{b}}$ Department of Civil and Environmental Engineering, University of Trento, Via Mesiano 77, I-38123 Trento, Italy \\ ${ }^{\mathrm{c}}$ Department of Energy Production and Use, Politehnica University of Bucharest, Splaiul Independentei 313, 060042 Bucharest, Romania
}

\section{A R T I C L E I N F O}

Article history:

Received 17 May 2012

Accepted 27 July 2012

Available online 22 August 2012

\section{Keywords:}

WEEE

Recycling

Regulation

Consumption

Reduction

\begin{abstract}
A B S T R A C T
The paper presents some data regarding waste electrical and electronic (WEEE) management in one of the founding countries of the EU, Italy, and in a recent entry into the EU, Romania. The aim of this research was to analyze some problems that countries entering the EU will have to solve with respect to WEEE management. The experiences of Italy and Romania could provide an interesting reference point. The strengths and weaknesses that the two EU countries have encountered can be used in order to give a more rational plan for other countries. In Italy the increase of WEEE collection was achieved in parallel with the increase of the efficiency of selective Municipal Solid Waste collection. In Romania, pilot experiences were useful to increase the awareness of the population. The different interests of the two populations towards recyclable waste led to a different scenario: in Romania all types of WEEE have been collected since its entrance into the EU; in Italy the "interest" in recycling is typically related to large household appliances, with a secondary role of lighting equipment.
\end{abstract}

(c) 2012 Elsevier Ltd. All rights reserved.

\section{Introduction}

Italy is one of the founding members of the European Union, being one of the seven countries that formed the European Coal and Steel Community in 1952, the European Economic Community (EEC) in 1957, which, in 1992, became the EU. During these decades significant EU directives were issued, with a growing interest in environmental problems. Waste management was one of the environmental sectors that took advantage of this evaluation.

The EU regulation, restricting the use of hazardous substances in electrical and electronic equipment (Directive 2002/95/EC) and promoting the collection and recycling of such equipment (Directive 2002/96/EC) has been in force since February 2003. The EU Directive provides for the creation of collection schemes where consumers return their used e-waste free of charge. The objective is to increase the recycling and/or re-use of such products. It also requires heavy metals such as lead, mercury, cadmium, chromium and flame retardants such as polybrominated biphenyls (PBBs) or polybrominated diphenyl ethers (PBDEs) to be replaced by safer alternatives. Despite such rules on collection and recycling, only one-third of electrical and electronic waste in the European Union is reported as being appropriately treated, and the other two thirds go to landfills and potentially to sub-standard treatment sites in or outside the EU

\footnotetext{
* Corresponding author. Tel.: +39 0332 218782; fax: +39 0332218779

E-mail address: vincenzo.torretta@uninsubria.it (V. Torretta).
}

(Eur-Lex, 2008). The collection target of $4 \mathrm{~kg}_{\text {WEeE }}$ inhab ${ }^{-1} \mathrm{y}^{-1}$ set by the directive 2002/96/EC does not properly reflect the situation in individual Member States. For example, Italy and Romania are two of the European Countries that have not reached the target for 2008 (2.6 $\mathrm{kg}_{\text {WEEE }}$ inhab $^{-1}$ and $0.8 \mathrm{~kg}_{\text {WEEE }}$ inhab ${ }^{-1}$ respectively), while $7.8 \mathrm{~kg}_{\text {WEEE }}$ inhab $^{-1}$ was collected in Germany, $6.9 \mathrm{~kg}_{\text {WEEE }}$ in$\mathrm{hab}^{-1}$ in the UK, $6.3 \mathrm{~kg}_{\text {WEEE }}$ inhab $^{-1}$ in Spain, $4.4 \mathrm{~kg}_{\text {WEEE }}$ inhab ${ }^{-1}$ in France and almost $10 \mathrm{~kg}_{\text {WEeE }}$ inhab $^{-1}$ in Norway, Sweden and Finland (Eurostat, 2012). WEEE needs a specialized collecting, transport, treatment and final disposal system (Ciocoiu et al., 2010).

In both Romania and Italy, it is certain that part of the WEEE flux follows an incorrect path and thus does not contribute to the specific separated collection. In fact, considering the above mentioned data, we must also remember and take into account the illegal trade of electrical and electronic waste to non-EU countries (Ladou and Lovegrove, 2008; Tompson and Chainey, 2011) which continues to be widespread even though the Basel Convention regarding the movements of hazardous wastes has been in force since 1992. However in the last few years, countries such as China, India and others have adjusted their laws to fight WEEE imports (Joshef, 2007; Dwivedy and Mittal, 2010; Chung and Zhang, 2011; Ongondo et al., 2011; Townsend, 2011).

As the national transposition of the WEEE Directive varies between the member states, a patchwork of requirements and compliance solutions is emerging across Europe.

Extended Producer Responsibility (EPR) has been introduced as an environmental policy approach, in which the producer's 
responsibility for a product is extended to the post-consumer stage of the product life cycle, including its final disposal.

If WEEE is inadequately treated it can pose major environmental and health problems. For this reason, in December 2008, the European Commission revised the directives on electrical and electronic equipment (EEE) in order to tackle the fast increasing stream of WEEE. The result is the Directive 2008/34/EC. The aim of this directive is to increase the amount of WEEE that is appropriately treated, to reduce the amount that will go on to final disposal, but also to reduce the administrative burden. Two collection targets have been proposed: one equal to $45 \%$ of the average weight of EEE placed on the market by 2013 , and the other equal to $65 \%$ by 2016 in each Member State.

To have an idea of the required effort, considering data provided by Eurostat, in Italy in the year 2008, the potential market of EEE regarding types R1 and R2 (refrigerators, conditioners dishwashers, washing machines, ovens, etc.) was almost 641,000 tons and the separate collection around $16.5 \%$ only. Types R1 and R2 were less than the half of the total EEE, but were the only EEE involved in source separation activities (with the exception of lighting equipment). In the same period Romania showed lower values for R1 and R2 collection (5.5\%), but the source separation activities involved all the EEE types (Eurostat, 2012).

In practice, Italy must change from a situation of less than $4 \mathrm{~kg}_{\text {WEEE }} \mathrm{y}^{-1}$, required in 2008 , to $10.9 \mathrm{~kg}_{\text {WEEE }} \mathrm{y}^{-1}$ and 16.4 $\mathrm{kg}_{\text {WEEE }} \mathrm{y}^{-1}$ set as targets for 2013 and 2016, respectively (Huisman, 2010). The targets for Romania (5.7 $\mathrm{kg}_{\text {WEEE }} \mathrm{y}^{-1}$ and $9.9 \operatorname{kg}_{\text {WEEE }} \mathrm{y}^{-1}$ ) seem to be easier but it must be taken into account that this country entered the EU in 2007 (Huisman, 2010). Compared to the other countries that became part of the EU long before Romania, the targets imposed for Romania seem to be slightly more realistic because the starting point from which Romania can be held responsible for the WEEE generation and disposal is 2007 when it became an automatic obligation for the country to comply with the EU regulations and targets regarding WEEE. The EU regulation has taken into account the fact that a more drastic target for Romania would be difficult to reach in such a short period.

We thought it would be more interesting to evaluate and to compare the situations in Romania and in Italy, instead of the other of the 27 member states, because these countries failed to meet the 2008 WEEE target. The reason for this failure in Italy was a lack of organization, information and responsible use of economic funds to put into practice the above mentioned points with the obligation of member states under the WEEE directive. In particular, the lack of information about the location of the few collection points and the habit of considering the landfill the main solution of disposal was a great obstacle. The information about the availability of collection points close by is very important. Gutierrez et al. (2008) analyzed the environmental impact of disposing of waste electrical appliances and concluded that, under current regulatory practices, the distance to the recycling facility plays a key role in determining whether recycling is more environmentally-friendly than landfill disposal. The study made clear recommendations on the maximum distances to travel to collect and dispose of electrical waste to avoid negative environmental impacts.

The fast economic development that Romania has shown in the last few years has multiplied the number of environmental problems to be faced. These problems and the consequent difficulties can be expected also in the future EU new entries.

As a result of their failure to achieve the objectives, the two countries have dedicated great effort to organize WEEE collection, and, in a short time, have achieved very encouraging results. There are countries that must implement WEEE collection (although Italy has had this obligation much longer than Romania) that can also take inspiration from the mistakes and shortcomings highlighted in Romania and Italy in the past, by considering the experience of these countries since 2008 , which, nonetheless has yielded positive results.

\section{WEEE in Romania and Italy}

The quantity of WEEE produced per year in Europe has already reached 10 million tons (UNU, 2007). Taking into account the gross domestic product (GDP) and the quantity of WEEE produced in Italy and Romania, it is clear that the amount of waste to be managed is "proportional" to the economic development of a country: in Italy in 2006 the GDP was $31.3 \mathrm{kUSD}^{\text {inhab }}{ }^{-1}$ with a per-capita WEEE of $17.6 \mathrm{~kg} \mathrm{y}^{-1}$ while in Romania the GDP in 2007 was 7.9 kUSD inhab ${ }^{-1}$ with a per-capita WEEE of $5.5 \mathrm{~kg} \mathrm{y}^{-1}$. This situation was not stable as the economy in Romania showed rapid development. Indeed, with respect to the EEE placed on the market, in Romania the forecast for 2014 is around $16 \mathrm{~kg}_{\mathrm{EEE}}$ inhab ${ }^{-1} \mathrm{y}^{-1}$, while in Italy it is around $25 \mathrm{~kg}_{\mathrm{EEE}}$ inhab ${ }^{-1} \mathrm{y}^{-1}$ (Huisman, 2010). These values represent an increase of less than $10 \%$ for Italy compared to 2008 , but for Romania the increase is around $50 \%$. In the various EU countries the WEEE collection tends to improve every year. Although some equipment is sent for recycling, the annual volume of waste generated is increasing to between 3\% and 5\% in Europe alone. The annual estimate has exceeded 6 million tons and is expected to rise to 12 million tons by 2015 , equivalent to $14 \mathrm{~kg}$ per person per year (Barba-Gutiérrez et al., 2008).

France, Germany, Belgium, Holland and the UK started WEEE collection earlier than Italy and Romania and now have a better per-capita separate collection (Huisman, 2010).

\subsection{Romania}

In Romania, the WEEE management system developed in a short period of time. After becoming a candidate and then a member of the European Union, Romania transposed the European regulations into its national legislation (Ciocoiu and Tartiu, 2012).

Before the application of the 2002/96/EC Directive, WEEE management in Romania was very unclear. There is not a lot of data regarding this problem, but because Romania started the implementation of selective waste collection only recently; before that, WEEE could be found together with other types of wastes in the landfills. However, in Romania each inhabitant owns about $30 \mathrm{~kg}_{\mathrm{EEE}}$ with a lifetime almost double compared to other EU countries (ISPE, 2006).

Since 2006, the quantity of WEEE that must have been collected for the Member States has been set to $4 \mathrm{~kg}_{\text {WEEE }}$ inhab ${ }^{-1} \mathrm{y}^{-1}$. Taking into account the impossibility of reaching this target, Romania asked for a transition period of 2 years (ISPE, 2006). Romania is not the only country in Europe in this situation; countries in Central and Eastern Europe, as well as some Baltic Countries, have asked for a postponement of the deadline. The reasons were varied and related to: the population's limited ownership of electrical and electronic equipment, the long period of usage (because of low incomes), and the difficulties of the population that live in the rural areas (high percentage) to create a collection infrastructure (ISPE, 2006).

In 2004, Romania established intermediary collection objectives, from 2 to $4 \mathrm{~kg}_{\text {WEEE }}$ inhab ${ }^{-1} \mathrm{y}^{-1}$ by 2007 , through the WEEE implementation plan (Annex 4 - Implementation Plan for DIRECTIVE 2002/96/EC on waste electrical and electronic equipment (MININD, 2004)).

The demographic characteristics (total population, density, age structure) play a key role. An increasing consumption determines the need for resources, goods and services, directly influencing the pressure on the environment. During 1990-2008, Romania's population decreased from $23,211,395$ inhabitants, to $21,565,119$ 
inhabitants, thus registering a fall of $7.25 \%$. In the same period the GDP increased significantly. According to the National Institute of Statistics, in 2008, of the 21,537,563 inhabitants of Romania, 55\% were urban, while $45 \%$ were rural residents. The highest population density, 1222.37 inhab km${ }^{-2}$ was recorded in Bucharest - Ilfov region, and the lowest density, 60.07 inhab $\mathrm{km}^{-2}$, was recorded in the Western Region (Ciocoiu et al., 2010). It is clear that in the areas with a high population density, WEEE management must be different compared to the areas with a low population density. In 2010, with the G.D. No. 1037/2010, which replaced the H.G. No. 448/2005, Romania imposed the following objectives for WEEE:

- prevention of WEEE and reuse, recycling and other forms of recovery of these types of waste to reduce the quantity of waste disposed of;

- improvement of the environmental performance of all operators involved in the life cycle of EEE (producers, distributors and consumers) and, in particular, economic agents directly involved in the treatment of waste electrical and electronic equipment.

The directive application involved the setting up of over 30 nonprofit collective organizations, grouped to form a WEEE Forum that covers most of the EU member states. According to the WEEE Forum data, the waste from the first category (large household appliances, small household appliances, IT and telecommunications equipment, consumer equipment, lighting equipment, electrical and electronic tools, toys, leisure and sports equipment, medical devices, monitoring and control instruments, automatic dispensers) have a weight of about $46 \%$ of the total. From this data, the total quantity of WEEE that will be generated in Romania starting in 2009 was assessed, as well as the collected quantity of WEEE, taking into account a collection rate of $58 \%$ from the generated quantity of the best systems (ME, 2009). For example, for the level of region 3, the assessment for the next years is presented in Table 1 (ARPMAG, 2006).

At the beginning of 2006, Romania started the procedure of registering producers of EEE in the Electric and Electronic Equipments Producers and Importers Register to comply with the requirements of the legislation in force. By the end of 2009, 1,351 producers of EEE had been registered (ME, 2009).

In 2009, an amount of $123,766.98$ tons EEE was put onto the market. Their distribution by category is shown in Table 2 (ANMP, 2010). In 2009, about 38,700 tons of WEEE was collected. Of the total collected quantity, 95\% was treated (ANMP, 2010; RoRec, 2012). The other $5 \%$ was sent to a landfill if it could not be treated.

The overall Romanian picture is presented in Fig. 1.

\subsection{Italy}

With the Decree No. 151, of July 2005, the Italian government converted the WEEE Directive 2002/96/EC and the EU Directive RoHS 2002/95/EC into law. The WEEE Directive requires producers to recycle waste and electronic equipment; the Directive on the Restriction of Hazardous Substances (RoHSs) bans the use of certain hazardous substances in electrical and electronic products.

In addition to Italian law No. 151/2005, on waste management, there is law No. 152/2006, part 4, and law No. 59/2008. Moreover,

Table 1

Total quantity of WEEE generated in region 3 of Romania $\left(\mathrm{kg}\right.$ inhab $\left.{ }^{-1} \mathrm{y}^{-1}\right)$.

\begin{tabular}{lllllllll}
\hline Year & 2006 & 2007 & 2008 & 2009 & 2010 & 2011 & 2012 & 2013 \\
\hline $\begin{array}{c}\text { Total WEEE } \\
\text { generated } \\
\text { quantity }\end{array}$ & 7.35 & 6.87 & 6.42 & 6 & 5.61 & 5.24 & 4.9 & 4.58 \\
\hline
\end{tabular}

Table 2

EEE producers at Romanian regional levels.

\begin{tabular}{lc}
\hline Regions & Producers number \\
\hline Region 1 & 79 \\
Region 2 & 28 \\
Region 3 & 24 \\
Region 4 & 29 \\
Region 5 & 42 \\
Region 6 & 92 \\
Region 7 & 42 \\
Region 8 & 265 \\
\hline
\end{tabular}

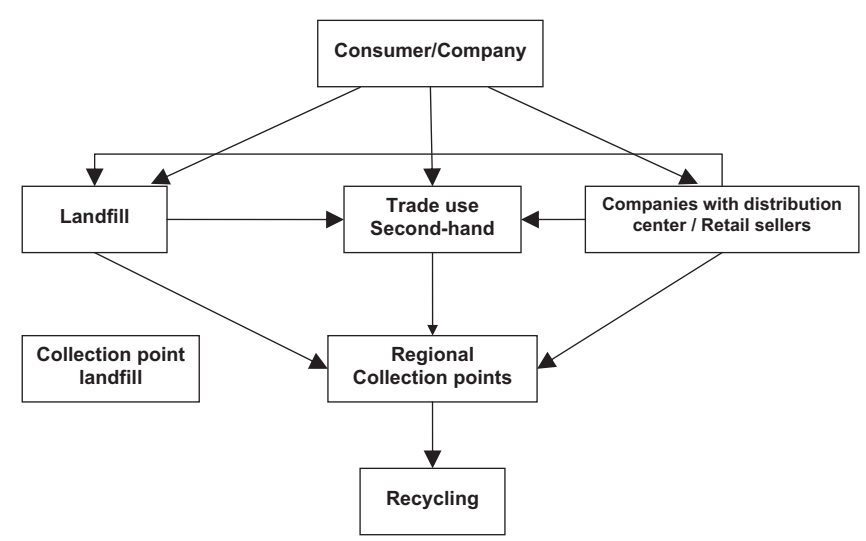

Fig. 1. WEEE scheme in Romania.

the Ministerial Decree No. 8/3/2010 introduced simplified procedures for factories that withdraw WEEE, while compulsory withdrawal (one-to-one principle) is regulated by Ministerial Decree No. 17/12/2009. This regulation divides the WEEE on the basis of the manufacturing date: there is the so called "historical" (built before January 1st 2006) and the "current" WEEE (built after that date).

There is no obligation to withdraw historical WEEE, while for the current there is another classification based on the owner's category:

- Domestic WEEE (from domestic use) to be freely sent to collection centers.

- Professional WEEE (from factory use) to be collected by an authorized waste collector.

The Ministerial Decree No. 185/2007 grouped WEEE into five main groups according to the type of treatment, environmental dangerousness, and to how easy separation was at the collection centers:

- R1: Refrigerators and air conditioning systems.

- R2: Large household appliances.

- R3: TV sets and displays.

- R4: Small household appliances, consumer electronics, office automation, computer appliances, lighting devices.

- R5: Light sources (no incandescent lamps).

In order to offer financial support for WEEE treatment and final disposal, it is possible to apply a WEEE eco-contribution to every new device sold. This eco-contribution may be applied openly to the "big whites" (refrigerators, washing machines, dish washers) until February 13th 2013. Otherwise, the producers may include, in the selling price, the fee for appropriate WEEE disposal.

For professional WEEE, the producer/distributor has to join a consortium or another organization which provides WEEE disposal; the membership requires the payment of an annual fee. After the 


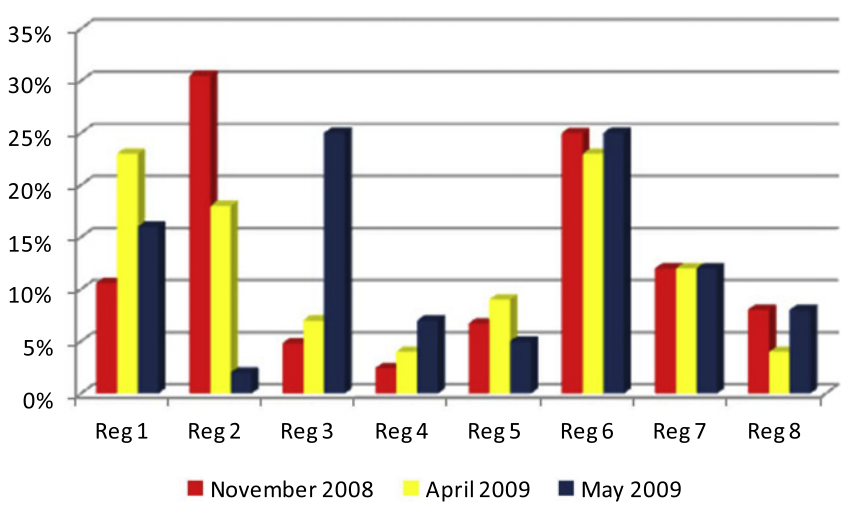

Fig. 2. Percentages of WEEE collection during the event at the end of 2008 and during the first and second event in 2009.

payment of the annual fee, the consortium must collect the WEEE for free. The national regulation provided for the creation of Collection Systems: these are consortiums directly financed by the producers on the basis of the number of goods sold on the public market. Consortiums provide the organization for all the necessary activities for the correct management and disposal of the WEEE, guaranteeing the fundamental safety standards in the treatment and disposal process and the achievement of a high level of material recovery.

\section{Results and discussion}

\subsection{The situation in Romania}

Since the 2002/96/EC Directive had been absorbed into the national regulatory framework, the Romanian Ministry of Environment and Sustainable Development has already organized seven major events (two in 2007, three in 2008 and two in 2009), the purpose of which has been to collect WEEE on a specific day at the national level. These events were called the "Big release" (Marea Debarasare in Romanian). In Romania it was decided to construct 1 collection point in each county, one collection point in each town with more than 100,000 inhabitants, and six collection points in Bucharest. As a result of the event in November 2008, on the dedicated day, a total amount of $557,457 \mathrm{~kg}_{\text {WEEE }}$ was collected. The percentages obtained for each of the eight Romanian regions for the last three events are presented in Fig. 2. It must be specified that from the administrative point of view Romania, is divided into 41 counties, plus the area near the capital Bucharest, and from the economic point of view, it is divided into eight development regions: NorthEast region (region 1), South-East region (region 2), South region (region 3), South-West region (region 4), West region (region 5),
North-West region (region 6), Central region (region 7), Bucharest-Ilfov region (region 8 ). In Fig. 2, the eight regions mentioned on the OX axis are the ones presented above.

In Bucharest, the selective collection of WEEE accounted for a significant percentage during the last events. The quantities of WEEE collected in all six sectors of Bucharest, for the events since 2009, are presented in Fig. 3.

According to the Romanian Association of Recycling, the quantity of WEEE collected in March 2011 was about 270 tons from 28 counties. Therefore, in only 3 months of 2011, the WEEE collected exceeded the quantity of 2010. In May 2011, over $85 t_{\text {WEEE }}$ was collected together with the authorities from 16 counties with over 230 cities.

Regarding the quantity of WEEE generated in Romania, according to United Nations University report, this will continue to grow also in the period 2010-2020 (Ciocoiu et al., 2010). The expected amount of WEEE generated by households in the 2010-2020 period for Romania will be: in 2010, 134,670 $t_{\text {WEEE, }}$ in 2014, $165,403 t_{\text {WEEE, }}$ in $2015,174,466 t_{\text {WEEE }}$ and in 2020, 226,702 $t_{\text {WEEE. }}$ So, the amount of WEEE generated is expected to grow significantly, almost doubling in 10 years. There are no forecasts for WEEE quantities to be collected and treated in Romania, but the existence of an international treatment factory, and the emergence of other private initiatives in this area is a prerequisite for an increase in their recovery (Ciocoiu et al., 2010).

One of the Romanian weaknesses regarding WEEE collection is also due to the fact that the average operating life in Europe for large appliances is of 8-10 years, while in Romania the life is $13-17$ years. In some rural areas, there are even 50-year-old appliances in some old households. Using equipment far beyond the average time recommended by the manufacturer is a result of the economic situation (low minimum wages, high percentage of people whose monthly income is less than $€ 200$, etc.) and the Romanian "tradition" (Ciocoiu et al., 2010).

\subsection{The situation in Italy}

Before 2008, Italy had many difficulties in falling in line with the major countries of the EU as regards separate WEEE collection. These difficulties were due to several factors, such as the lack of clear regulations, the lack of funds to cover organizing the collection and a failure to comply with the waste regulations, which often characterized large parts of the country. Standard adaptation, WEEE collection implementation and other collection systems were enabled to overcome these difficulties.

After a first phase, during which the separate collection in Italy was able only to achieve a limited result, great effort was made to organize the sector of the separate collection and treatment of

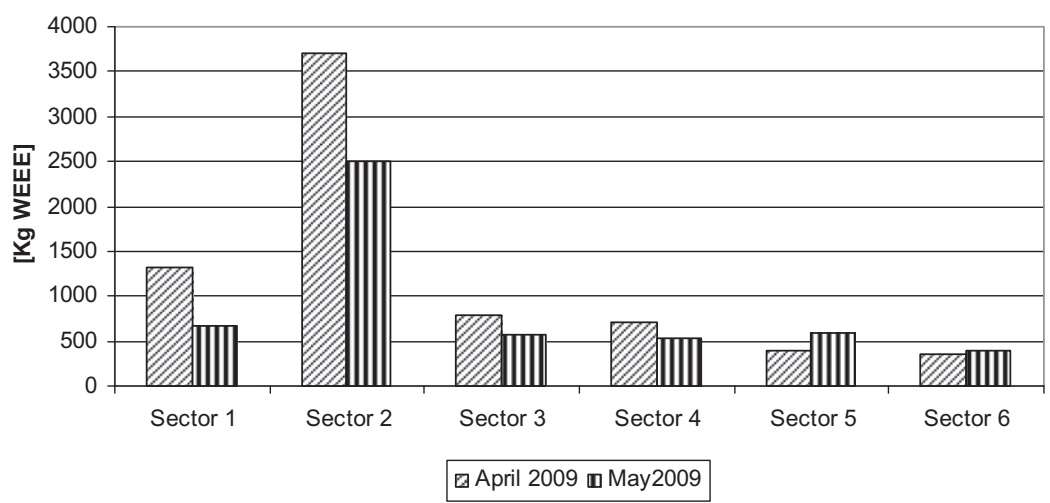

Fig. 3. Comparison between WEEE quantities collected in the two events since 2009 in Bucharest. 
Table 3

Recovery of other materials through the WEEE separate collection in Italy in 2008.

\begin{tabular}{llr}
\hline Materials & Industrial recovery (\%) & Quantity (tons) \\
\hline Iron & 43.04 & 83181 \\
Glass & 17.88 & 34558 \\
Aluminum & 1.97 & 3811 \\
Plastics & 25.57 & 49419 \\
Other recyclable materials & 2.99 & 5782 \\
Other not recyclable materials & 8.54 & 16504 \\
\hline
\end{tabular}

WEEE, seeking the involvement and strong cooperation of the citizens, also starting initiatives in schools and arranging a specific delivery point for WEEE in all the collection areas (ecopoints, ecological islands). The aim of the educational activities was to identify possible actions that could help citizens to reduce waste by means of a coordinated activity.

Separate WEEE collection started operating, in Italy, in 2008. Until that date, the collection was operated by different, uncoordinated bodies, in a very un-effective way. Since 2009, the situation has improved remarkably. In the last 3 years, WEEE collection increased from $65,000 \mathrm{t}_{\text {WEEE }} \mathrm{y}^{-1}$ to $260,000 \mathrm{t}_{\mathrm{WEEE}} \mathrm{y}^{-1}$ in 2010. In terms of weight, the largest part consists of R1 and R2 category WEEE. WEEE management made it possible to recover 83,000 tons of iron, 50,000 tons of plastics, 3,800 tons of aluminum, but it also prevented the release of $2,670,000$ tons of carbon dioxide into the atmosphere (Table 3) (ECODOM, 2008).

From a geographical point of view, 55\% of the total WEEE collection took place in Northern Italy. The Lombardy Region leads the ranking of the virtuous Regions, collecting $14.6 \%$ of the total, followed by the Piedmont Region (10.5\%) and the Veneto (10.1\%). Among the central and southern Italian Regions, the most active are Tuscany (9\%) and Lazio (8.5\%) (CDCRAEE, 2011).

In 2010, Italy achieved and exceeded the European target for WEEE collection, set to $4 \mathrm{~kg}_{\text {WEEE }}$ inhab ${ }^{-1} \mathrm{y}^{-1}$. During this year more than 245,000 $t_{\text {WEEE }}$ was collected: comparing this data with that of the year 2009 , there was a $27 \%$ increase. The data relating to year the 2008 (65,000 tWEEE collected) highlights a very considerable increase (Fig. 4).

\subsection{Comparison}

Some considerations can be made from the experiences of Romania and Italy:

- a significant improvement of results in WEEE separate collection has been obtained since 2008, thanks to an intense campaign to inform the population of the importance of WEEE

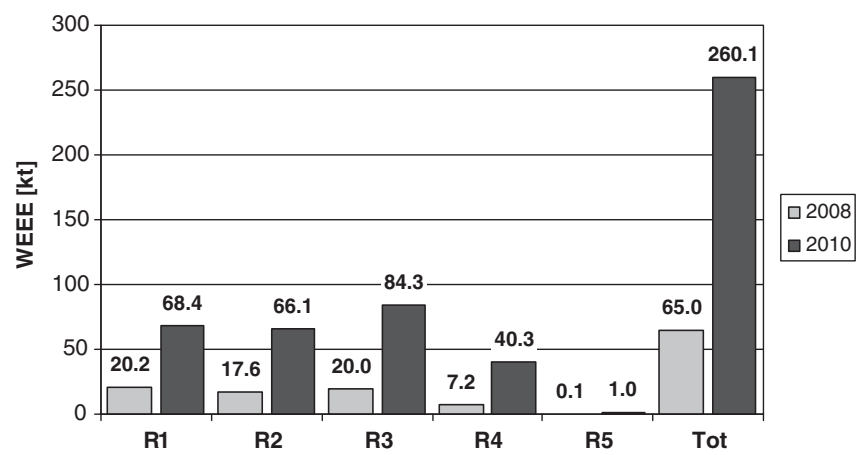

Fig. 4. Quantities (tons) of WEEE collected during 2010 in Italy and comparison with those of 2008 . collection, and of how and where to dispose of it, and to support and encourage sustainable consumption (a relevant role has been taken by Consortia and relative websites);

- the effort to support the information and to educate on better behavior moves in parallel with the adjustment and improvement of the national laws, in accordance with the EU directives and with the availability of funds to improve the WEEE separate collection.

In both cases the role of communication is significant.

Another important aspect to be improved in both cases regards the need to extend manufacturers' responsibility (EPR) for their products beyond the point of sale, to end-of-product-life. Currently this principle is being sought in both Countries, but it needs to be applied better, improving its applicability in the area of the endof-life management of electronic and electrical equipment, following advanced situations, such as Switzerland (Khetriwal et al., 2009).

There is another aspect that is common to Italy and Romania, as well as to other countries that are about to join the EU: there is a huge difference between different regions in the same country. Similar considerations can be extended to other, important EU counties, such as Spain, where a specific study revealed large differences between autonomous communities (Queiruga et al., 2012).

Following the experience of Romania and Italy, different aspects can be considered for other countries. In the case of high income countries, communication campaigns should be oriented to reminding the citizens that the activated system must be "exploited". In the case of transient economies, communication campaigns should take into account the big differences of "audience" that can be found between urban and rural areas; one important aspect is the adoption of incentives/prizes for citizens/ municipalities that demonstrate the best results when participating in the initiatives.

Some other considerations can be made starting from the experiences of Romania and Italy and considering the situation of transient economies and/or new EU entries:

- the increases in collection rates in high income countries, where WEEE management has been faced, should decrease steadily;

- an initial peak in the collection must be expected in transient economies that have to start a WEEE collection strategy;

- on the cost of WEEE management, in high income countries, a self-sustained system can be a reality. In transient economies, pilot experiences that give a boost to the sector can be supported by structural funds (for example EU structural funds);

- it is very important to plan every action (particularly on waste collection) supported by a strong information campaign and the education of the population;

- in co-organized areas like the EU, exemptions for new entries are necessary as adequate collection rates can be reached only after a lag phase of a few years;

- the environmental impact of WEEE can be kept low in high income countries also through the promotion of technological enhanced equipment design. The additional costs for these enhancements would not be acceptable for buyers in transient economy countries, and therefore, the priority in terms of the environment should be the collection and management of old equipment with a high impact.

\section{Conclusions}

WEEE collection is becoming increasingly relevant in countries, such as Romania, that show an increase in GDP. Indeed, economic development changes the habits of the population both in terms of the domestic use of EEE, and in terms of the lifetime of these 
devices. Therefore, the effort for WEEE collection depends also on the economic situation of a country. Cases like Romania can take advantage of the availability of structural funds, but the aim must be to achieve a self-sustained system of WEEE collection, based on the responsibility of producers and on the adoption of incentives/ prizes for citizens/municipalities that demonstrate the best collection results.

In Romania, a successful strategy was based on pilot campaigns to increase the awareness of the population. These campaigns cannot be the means of providing the population with information: waste management consortia and their websites must also play a significant role.

The different traditions in Romania and Italy, with respect to recycling, led to different scenarios: in Romania, since its entry into the EU, all WEEE types have been collected, but in Italy the interest in recycling is typically related to large household appliances. Taking into account the evolution of the composition of WEEE, it is clear that, today, a focus also on lighting equipment is central to an optimized strategy.

The experience of organizing WEEE collection in countries like Italy can provide a good reference point for emerging countries for optimizing the timing and structure of the regulation.

In both cases, the WEEE sector shows interesting potential for material recovery that can be included in the concept of urban mining.

\section{References}

ANMP - Romanian National Environmental Protection Agency, 2010. Regional waste management plan for region 8 Bucharest. Ilfov, Regional Environmental Protection Agency Bucharest. <http://www.arpmb.ro> (accessed in 2012)

ARPMAG - Romanian National Environmental Protection Agency, 2006. <http:// www.arpmag.anpm.ro/> (accessed in 2012).

Adenso-Díaz, B., Barba-Gutiérrez, Y., Hopp, M., 2008. An analysis of some environmental consequences of European electrical and electronic waste regulation. Resour. Conserv. Recycl. 52 (3).

CDCRAEE - Italian WEEE coordination center, 2011. Collection and processing of WEEE in Italy (Ritiro e trattamento dei rifiuti da apparecchiature Elettriche ed elettroniche in Italia). <http://www.cdcraee.it> (accessed in 2012).

Chung, S.S., Zhang, C., 2011. An evaluation of legislative measures on electrical and electronic waste in the People's Republic of China. Waste Manage. 31 (12), 2638-2646.

Ciocoiu, N., Tartiu, V., 2012. The role of informal sector within WEEE management systems: a Romanian perspective. Theor. Empirical Res. Urban Manage. 7 (1), 27-38.

Ciocoiu, N., Burcea, S., Târtiu, V., 2010. The WEEE management system in Romania Dimension, strengths and weaknesses. Theor. Empirical Res. Urban Manage. 6 (15), 5-22.
Dwivedy, M., Mittal, R.K., 2010. Estimation of future outflows of e-waste in India. Waste Manage. 30 (3), 483-491.

ECODOM - Italian consortium for recovery and recycling of WEEE, 2008. WEEE, the contribution of recycling to the Kyoto targets: Energy balance and environmental recovery of certain types of waste electrical and electronic, RAEE, il contributo del riciclo agli obiettivi di Kyoto Bilancio energeticoambientale del recupero di alcune tipologie di rifiuti elettrici ed elettronici) <http://www.ecodom.it> (accessed in 2012).

Eurostat, 2012. WEEE - Key Statistics and Data. <http://www.epp.eurostat. ec.europa.eu> (accessed in 2012).

Gutierrez, Y.B., Adenso-Diaz, B., Hopp, M., 2008. An analysis of some environmenta consequence of European electrical and electronic waste regulation. Resour. Conserv. Recycl. 52, 481-495.

Huisman, J., 2010. WEEE Recast: From 4 kg to 65\%: The Compliance Consequences. United Nations University, Bonn, Germany.

Khetriwal, D.S., Kraeuchie, P., Widmen, R., 2009. Producer responsibility for e-waste management: key issues for consideration - learning from the Swiss experience. J. Environ. Manage. 90 (1), 13-165.

ISPE - Institute for Studies and Power Engineering 2006. Research of the WEEE management costs and the determination of the number of the collection points for Romania) (Studiu pentru determinarea costurilor privind gestionarea deseurilor de echipamente electrice si electronice si determinarea numarului necesar de puncte de colectare in Romania) n. 362/2006. <http://www.icpe.ro> (accessed in 2012)

Joshef, K., 2007. Electronic waste management in india-issues and strategies. In: Proceedings of Eleventh International Waste Management and Landfill Symposium S. Margherita di Pula, Italy, 1-5 October, 2007.

Ladou, J., Lovegrove, S., 2008. Export of electronics equipment waste. Int. J. Occup. Environ. Health 14 (1), 1-10.

ME - Ministry of Environment, 2009. WEEE management in Romania (Gestionarea DEEE in Romania). Report of Romanian Ministry of Environment - Organization and Communication Directorate of the Ministry of Environment. <http:// www.mmediu.ro> (accessed in 2012).

MININD - Ministerul Economiei Comertului si Mediului de Afaceri, 2004. Annex 4 Implementation Plan for DIRECTIVE 2002/96/EC on Waste Electrical and Electronic Equipment. <http://www.minind.ro/> (accessed in 2012).

Ongondo, F.O., Williams, I.D., Cherrett, T.J., 2011. How are WEEE doing? A global review of the management of electrical and electronic wastes. Waste Manage. 31 (4), 714-730.

Queiruga, D., González Benito, J., Lannelongue, G., 2012. Evolution of the electronic waste management system in Spain. J. Clean. Prod. 24, 56-65.

RoRec - Romanian Recycling Association - RoRec, Media Room. <http:/ www.rorec.ro> (accessed in 2012).

Tompson, L., Chainey, S., 2011. Profiling illegal waste activity: using crime scripts as a data collection and analytical strategy. Eur. J. Crim. Pol. Res. 17 (3), 179-201.

Townsend, T.G., 2011. Environmental issues and management strategies for waste electronic and electrical equipment. J. Air Waste Manage. Assoc. 61 (6), 587610.

UNU - United Nations University, 2007. 2008 - Review of Directive 2002/96 on Waste Electrical and Electronic Equipment (WEEE) - Final Report, Study No. 07010401/2006/442493/ETU/G4. Contract No.: 07010401/2006/442493/ETU/ G4 ENV.G.4/ETU/2006/0032

Eur-Lex, 2008. Commission staff working paper accompanying the proposal for a directive of the European Parliament and of the Council on waste electrical and electronic equipment (WEEE) (recast) - Impact Assessment $\{\mathrm{COM}(2008) 810$ final $\} \quad\{\mathrm{SEC}(2008) \quad 2934\}, / * \mathrm{SEC} / 2008 / 2933$ final. $*$ (source http:/ eurlex.europa.eu/LexUriServ/LexUriServ.do?uri=CELEX:52008SC2933:EN:NOT) 